Research article

Open Access

\title{
Inflammation predicts accelerated brachial arterial wall changes in patients with recent-onset rheumatoid arthritis
}

\author{
Suad Hannawi ${ }^{1}$, Thomas H Marwick ${ }^{2 *}$ and Ranjeny Thomas ${ }^{1 *}$
}

\author{
1Diamantina Institute, University of Queensland, Princess Alexandra Hospital, Ipswich Road, Woolloongabba, Queensland 4102, Australia \\ 2Department of Medicine, University of Queensland, Princess Alexandra Hospital, Ipswich Road, Woolloongabba, Queensland 4102, Australia \\ * Contributed equally
}

Corresponding author: Ranjeny Thomas, r.thomas1@uq.edu.au

Received: 17 Dec 2008 Revisions requested: 14 Jan 2009 Revisions received: 16 Mar 2009 Accepted: 6 Apr 2009 Published: 6 Apr 2009

Arthritis Research \& Therapy 2009, 11:R51 (doi:10.1186/ar2668)

This article is online at: http://arthritis-research.com/content/11/2/R51

(c) 2009 Hannawi et al.; licensee BioMed Central Ltd.

This is an open access article distributed under the terms of the Creative Commons Attribution License (http://creativecommons.org/licenses/by/2.0), which permits unrestricted use, distribution, and reproduction in any medium, provided the original work is properly cited.

\begin{abstract}
Introduction Patients with recent-onset rheumatoid arthritis (RA) have impaired brachial artery endothelial function compared with controls matched for age, sex and cardiovascular risk factors. The present study examined endothelium-dependent (flow-mediated dilatation (FMD)) and independent (glyceryl trinitrate (GTN)-mediated dilatation (GMD)) structural responses in early RA patients, and determined progress over one year.

Methods Brachial artery FMD and GMD and carotid intima media thickness (cIMT) were studied using ultrasound in 20 patients diagnosed with early RA in whom symptoms had been present for less than 12 months, and in 20 control subjects matched for age, sex and established cardiovascular risk factors. FMD and GMD were re-assessed after 12 months in RA

patients and the change in each parameter was calculated. Data were analysed by univariate regression.

Results Mean FMD and GMD were significantly lower in early RA patients at baseline than in controls, but each parameter significantly improved in one year. FMD and GMD responses were positively associated with each other. Patients' age, Creactive protein (CRP) level and cIMT at baseline and CRP level at one year, were negatively associated with change in brachial responses in one year.

Conclusions Patients with recent-onset RA have altered brachial artery responses signifying both functional and structural abnormalities. However, early control of inflammation may reduce arterial dysfunction and thus the tendency for atherosclerotic progression.
\end{abstract}

\section{Introduction}

Patients with rheumatoid arthritis (RA) experience cardiovascular (CV) events more often than expected [1] and their mortality attributable to CV causes is increased [2]. Furthermore, ischaemic heart disease (IHD) has been found to occur about 10 years earlier in patients with RA compared with a population of patients with osteoarthritis matched for classical CV risk factors. Indeed, it has been suggested that RA itself is an independent risk factor for IHD [3]. The similarities which exist between the inflammatory/immunological reaction in RA and atherosclerosis raise the possibility that inflammatory mechanisms responsible for synovial lesions might also involve the vessel wall to facilitate the development of atherosclerotic lesions [4].
Although atherosclerosis can manifest as overt CV disease, it can be detected at an earlier stage by recognition of abnormal endothelial function and elevated carotid intima media thickness (cIMT) as measured by ultrasound. These measures correlate closely with direct measurement of local and systemic atherosclerotic burden in studies of pathology and with clinical CV endpoints [5,6]. Ultrasonographic assessment of the common carotid artery is a feasible, reliable, valid and cost-effective method for both population studies and clinical trials of atherosclerosis progression and regression [7]. We showed that cIMT is significantly higher in patients presenting with early RA than in controls matched for age, sex and CV risk factors [8].

CIMT: carotid intima-media thickening; CRP: C-reactive protein; CV: cardiovascular; DMARDs: disease-modifying anti-rheumatic drugs; ESR: erythrocyte sedimentation rate; FMD: flow mediated dilatation; GMD: GTN-mediated dilatation; GTN: glyceryl trinitrate; HAQ: health assessment questionnaire; HCQ: hydroxychloroquine; IHD: ischaemic heart disease; MTX: methotrexate; NO: nitric oxide; RA: rheumatoid arthritis; RF: rheumatoid factor; SD: standard deviation; SSZ: sulfasalazine; TNF: tumour necrosis factor. 
Endothelial function can be assessed by ultrasound as flowmediated vasodilatation of the brachial artery in response to increased vessel wall shear stress and mediated by nitric oxide (NO) release by endothelial cells $[9,10]$. Brachial artery vasodilatation can also be assessed by exogenous $\mathrm{NO}$ after sublingual glyceryl trinitrate (GTN) [11]. Post-GTN vasodilatation is considered endothelium-independent and predominantly mediated by smooth muscle. The dose-response curve for GTN-mediated vasodilatation has been examined in subjects with proven coronary artery disease and in healthy controls [12]. Patients with coronary disease had significantly reduced GTN-mediated vasodilatation, with the greatest difference observed with lower doses of GTN, suggesting that atherosclerosis is associated with functional abnormalities of both endothelium and vascular smooth muscle cells [12].

A previous study of 10 patients with early RA demonstrated impaired flow-mediated endothelial function, with improvement over six months of therapy [13]. Moreover, infliximab therapy improved endothelial-dependent vasodilatation, apparently through direct endothelial, rather than systemic effects [14]. In women without RA, treatment-associated improvement in endothelium-dependent vasodilatation has been shown to decrease the risk of subsequent $\mathrm{CV}$ events [15]. In longstanding RA, endothelial dysfunction is predicted by the C-reactive protein (CRP) level [15-19]. Other acute and chronic inflammatory states have also been shown to impair endothelial function [20-22]. In the current study, we studied a group of early RA patients, in whom cIMT had also been determined, and investigated the progression of endotheliumdependent and -independent brachial arterial function after one year.

Given the relationship of inflammation severity to atherosclerotic burden, as measured by cIMT and carotid plaque, at presentation with early RA [23], we hypothesised that inflammatory indices would predict arterial responses. Therefore, a group of conventional CV risk factors and indices of RA inflammatory disease were analysed at baseline and one year to determine their relationship to changes in brachial artery response.

\section{Materials and methods RA patients}

All 31 study participants met the American College of Rheumatology 1987 revised criteria for the classification of RA [24]. All the patients were enrolled from 2004 to 2005 with a diagnosis of RA with symptom duration less than 12 months. Patients attended an early RA clinic regularly, and received combination methotrexate (MTX), sulfasalazine (SSZ) and hydroxychloroquine (HCQ) [25], unless contraindicated, after diagnosis and active disease were confirmed. After diagnosis, patients were treated according to a response-driven step-up algorithm, as previously described [26], with the aim of achieving clinical remission [27-29]. Intra-articular but not oral corticosteroids were used to control inflammation in addition to disease-modifying antirheumatic drugs (DMARDs), as required.

At one year, 52\% were taking MTX, SSZ and HCQ, 6\% MTX and SSZ, 16\% MTX and HCQ, 10\% SSZ and HCQ and 6\% SSZ only, and $10 \%$ refused treatment. An additional 20 healthy subjects were recruited from the community, who could be matched for age, sex and CV risk factors against 20 of the early RA subjects. We matched against a database of more than 1000 individuals recruited in a primary prevention setting. The primary match was with the age and gender, after which we matched on number and type of risk factors on a categorical basis. Although exact blood pressure or lipid levels were not matched, we were able to match for hypertension and hyperlipidaemia, in addition to smoking status in almost all the cases.

\section{Study procedure}

The study was approved by the human research ethics committee at Princess Alexandra Hospital, Woolloongabba, and all subjects provided written informed consent. CV risk factors were ascertained among RA patients at baseline, as previously described [8]. RA disease activity parameters and laboratory measurements were assessed as previously described, at baseline and 12 months. Flow-mediated dilatation (FMD), GTN-mediated dilatation (GMD), cIMT and plaque were measured soon after the diagnosis of RA was confirmed; FMD and GMD were repeated after 12 months and as described [8].

\section{Vascular function testing}

Brachial artery flow and GMD testing was undertaken within one to four weeks after diagnosis and before commencement of DMARDs. Individual blood pressure and heart rate remained constant during the testing. No subject had ultrasound evidence of brachial artery atherosclerotic plaque. Ultrasonography was performed by a trained investigator $(\mathrm{SH})$ who was unaware of the subject's clinical data, using a highresolution ultrasound machine, according to the International Brachial Artery Reactivity Task force Guidelines [30]. Two patients were taking statins, one was taking an angiotensinconverting enzyme inhibitor and one patient was taking both. Although all four patients were taking a once daily dose of their medication, they were asked to postpone this medication until after the vascular ultrasound. No patient was taking aspirin or GTN treatment.

Subjects rested in a supine position in a quiet, dark, temperature-controlled room. A pneumatic cuff was placed around the upper forearm distal to the segment of brachial artery, scanned in longitudinal section 2 to $10 \mathrm{~cm}$ above the antecubital crease. Focus, depth and gain were individually set to optimise images of the lumen/arterial wall interface. A baseline scan was recorded for two minutes, followed by induction of hyperaemia by cuff inflation to $240 \mathrm{mmHg}$ for four minutes. The FMD scan commenced 30 seconds before release of the cuff, and 
continued for one minute afterwards. A second baseline scan was recorded 10 minutes later. The coefficient of variation (cv) was 0.18 for FMD. A tablet of GTN was administered sublingually in a standardised manner and recording was continued for a further four minutes for GMD. The cv was 0.17 for GMD. Measurement of the brachial artery diameter was synchronised with the $\mathrm{R}$ wave of the electrocardiogram, to avoid possible errors resulting from artery pulsation. FMD and GMD were expressed as the relative increase in brachial artery diameter during hyperaemia:

$100 \times[$ (post - hyperaemia diameter - basal diameter) / basal diameter $]$.

cIMT was measured using carotid duplex scanning and automated software as previously described [31]. The cv for cIMT was 0.2

\section{Statistical analysis}

In a preliminary evaluation, continuous variables were tested for normality of distribution; transformations were applied for non-normally distributed variables. Variables with normal distribution were expressed as the mean \pm standard deviation (SD) and categorical variables as percentages. Differences between the FMD and GMD in RA and control groups were compared using the two-sample (independent) Student's ttest for normally distributed data. Log transformations were applied to non-normally distributed data. Associations of FMD and GMD with age, continuous $\mathrm{CV}$ variables and disease activity variables were evaluated using linear regression analysis. Brachial reactivity improvement, inflammatory and RA disease activity markers and lipid profile were summarised using mean values for the baseline measures and compared with the mean values at one year using paired Student's t-tests. The differences between the mean values were examined by twosample Student's t-tests. Linear regression analysis examined univariate correlations, and two-sided values of $P<0.05$ were regarded as statistically significant. For all the analyses, Stata 9/SE (Stata Corp, College Station, TX, USA) statistical software was used [8].

\section{Results \\ Clinical features}

Thirty-one patients presenting with RA within 12 months of symptom onset (Table 1) were treated and followed clinically for one year. Of the patients, 90\% were Caucasian, 3\% were Australian aboriginal and 6\% Asian. Four patients had previous CV events, including one male with a previous transient ischaemic attack at 52 years of age, two males with a history of angina at the ages of 48 and 64 years, and one patient with myocardial infarction (MI) at age 48 years. Twenty of these RA patients could be matched for age, sex and CV risk factors against 20 healthy control subjects from a database of more than 1000 individuals recruited in a primary prevention setting.

\section{Baseline cIMT, FMD and GMD in 20 patients with early RA and 20 matched controls}

The mean age at the time of diagnosis was 45 years (range 23 to 64 years), with male patients significantly older than females (51.2 \pm 9.2 years vs. $40.2 \pm 10.7$ years, $P=0.03$ ). The mean duration of RA symptoms at the time of scanning was $6 \pm 3$ months (range 1 to 12 months). Mean FMD and GMD of the brachial artery were significantly lower in RA patients than in controls (Figure 1a). We repeated the analysis after removing patients with previous $\mathrm{CV}$ events and their matched controls, and the results did not differ (FMD $5 \pm 4$ vs. $11 \pm 7, P=0.001$ and GMD $11 \pm 6 \mathrm{~mm}$ vs. $17 \pm 8 \mathrm{~mm}, P=0.02)$.

\section{FMD and GMD annual change and determinants of progression}

The annual changes in FMD and GMD measured by ultrasound were determined. FMD and GMD improved significantly over one year (Figure 1b). Univariate analyses were carried out to determine $\mathrm{CV}$ risk factors or inflammatory factors which might contribute to these changes in vascular parameters in patients with early RA over the first year. Improvements in FMD and GMD over one year were correlated. Age, baseline CRP and baseline cIMT were negatively correlated with the change in both FMD and GMD (Table 2). CRP level at one year was also negatively associated with the change in FMD and GMD. Patients who presented with high CRP levels at RA disease onset were more likely to continue with high CRP levels by one year (data not shown, $P<0.03$ ). These data suggest that endothelial dysfunction is reversible with falling levels of CRP. In support of this idea, erythrocyte sedimentation rate (ESR) level at baseline exhibited a similar negative relationship with FMD progression, and rheumatoid factor (RF) positive patients were less likely to improve FMD (Table 2). There were no significant associations of FMD with health assessment questionnaire (HAQ), gender, smoking history, blood pressure or lipid levels. In contrast, history of smoking ever and smoking pack year history were negatively correlated with change in GMD, consistent with the utility of GMD as a structural measure of vascular disease (Table 2). There were no significant associations of GMD with HAQ, ESR, blood pressure, high-density lipoprotein or triglyceride levels.

\section{Discussion}

An increasing body of evidence indicates that atherosclerosis shares similarities with other inflammatory/autoimmune diseases; indeed, there are surprising similarities between the inflammatory response observed in atherosclerosis and RA [32-34]. The current study hypothesised that the severity of systemic inflammation would be associated with progression of arterial dysfunction in RA. Patients with RA are at significantly higher risk of death than an age-matched population [35] with CV disease as a major cause of increased mortality [1], and discovery of early interventions in RA disease that might influence atherosclerotic progression are essential to determine approaches that could in turn reduce the 
Table 1

Patient details at baseline and one year

Week $0 \quad$ Week $52 \quad P$ value

(mean + SD)

$19: 12$

Male:female

54 (23 to 78 )

Mean age (range, years)

28 (17 to 45$)$

Body mass index (range, $\mathrm{kg} / \mathrm{m}^{2}$ )

1.8 ( 1 to 12$)$

Disease duration, mean (range, months)

Tender joint count (out of 53)

Swollen joint count (out of 44)

Health assessment questionnaire score (maximum disability 24)

Physician's global assessment of disease activity (maximum 100)

Joint pain (VAS, maximum 100)

Rheumatoid factor level

Disease activity score, $4 \mathrm{v}$

Rheumatoid factor positive, $\mathrm{n}(\%)$

\section{Cardiovascular risk factors}

History of ever smoking, $\mathrm{n}(\%)$

History of current smoking, $\mathrm{n}(\%)$

History of hypertension, $\mathrm{n}(\%)$

History of diabetes mellitus, $\mathrm{n}(\%)$

History of hyperlipidaemia, n (\%)

History of myocardial infarction, $n(\%)$

History of angina, $n(\%)$

History of stroke and/or transient ischaemic attack, $n(\%)$

Family history of cardiovascular disease, $\mathrm{n}(\%)$

\section{Laboratory values}

Erythrocyte sedimentation rate $(\mathrm{mm} /$ hour $)$

C-reactive protein $(\mathrm{mg} / \mathrm{L}$, normal $<6)$

\begin{tabular}{|c|c|c|}
\hline $18(14)$ & $7.6(8.1)$ & $<0.001$ \\
\hline $15(8.9)$ & $5.0(9.3)$ & $<0.001$ \\
\hline 3.3 (3.5) & $1.8(2.7)$ & 0.006 \\
\hline 37 (27) & $26(28)$ & 0.013 \\
\hline 51 (32) & $24(26)$ & $<0.001$ \\
\hline $281(438)$ & 98 (127) & 0.011 \\
\hline $4.3(1.6)$ & $2.6(1.4)$ & $<0.001$ \\
\hline $21(68 \%)$ & $17(55 \%)$ & \\
\hline $20(65 \%)$ & - & - \\
\hline $8(26 \%)$ & - & - \\
\hline $6(19 \%)$ & - & - \\
\hline $3(10 \%)$ & - & - \\
\hline $2(6.5 \%)$ & - & - \\
\hline $1(3.2 \%)$ & - & - \\
\hline $2(6.5 \%)$ & - & - \\
\hline $1(3.2 \%)$ & - & - \\
\hline $6(19 \%)$ & - & - \\
\hline $40(25)$ & $21(16)$ & $<0.001$ \\
\hline $27(25)$ & $9.3(12)$ & $<0.001$ \\
\hline
\end{tabular}

Bold values are statistically significant. $\mathrm{SD}=$ standard deviation; VAS $=$ visual analogue scale.

subsequent risk of CV mortality. Of importance, the current studies clearly demonstrate the effect of early DMARD intervention, and the effect of reduction in CRP on vascular endothelial dysfunction and GTN-mediated brachial arterial function during the first year of RA. Furthermore, while each vascular measurement indicates a different aspect of vascular dysfunction - FMD is a measure of endothelial function $[9,10]$ and GMD of smooth muscle damage [12] - each was reversible with treatment, and annual changes in each measure were correlated.

Arterial compliance is contributed by the arterial media layer, with abnormalities resulting from combined endothelial and smooth muscle damage [36]. Reduction in CRP in patients with RA was associated with substantial and significant improvement in both endothelium-dependent and endothelium-independent skin microvascular dysfunction [37,38]. A similar improvement in FMD and GMD occurred after treatment of early RA patients in the present study.

Disease activity and functional impairment are predictive of mortality in RA. Thus, if effective therapy could be introduced prior to the development of arterial damage, outcome could be improved. It has been demonstrated extensively that early therapeutic intervention with anti-rheumatic drugs improves the prognosis of RA [39], and that disease duration is a significant 
Figure 1
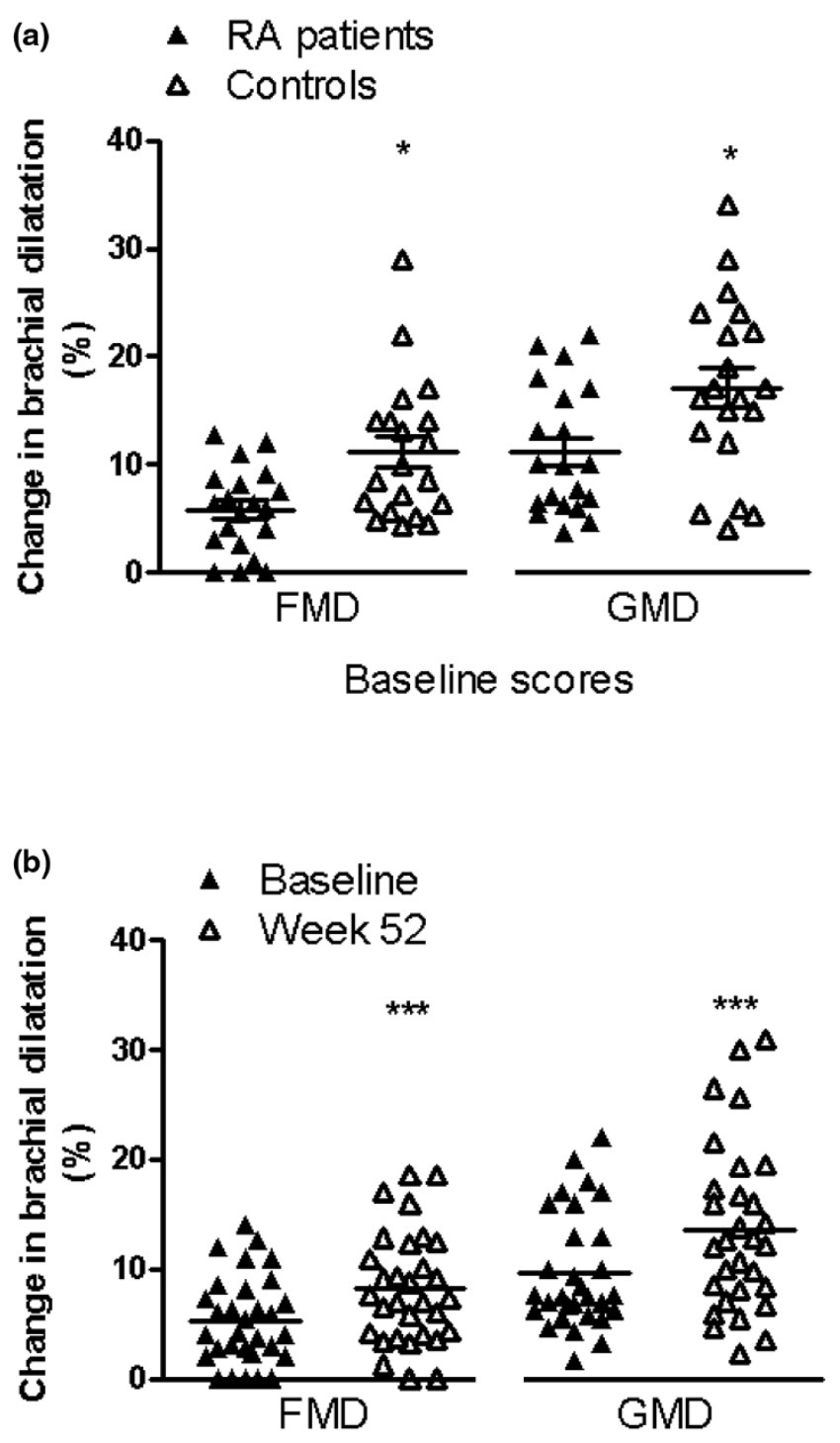

RA patients

Brachial dilatation of 20 patients with early RA and matched controls, and of 31 patients with early RA at baseline and one year. Flow-mediated and GTN-mediated dilatation of the brachial artery was measured using ultrasound as described in the methods. Results presented as mean \pm standard deviation. Flow mediated vasodilatation, $100 \times$ (posthyperaemic diameter-basal diameter)/basal diameter, GTN-mediated dilatation, $100 \times$ (post-GTN diameter-basal diameter)/basal diameter. (a) RA patients are compared with healthy controls matched for age, sex and CV risk factors. (b) RA patients are compared at baseline and after one year of treatment with anti-rheumatic drugs. FMD = flow-mediated dilatation; GMD = GTN-mediated dilatation; GTN = glyceryl trinitrate; $\mathrm{RA}=$ rheumatoid arthritis.

determinant of response to therapy [40]. The strategy of combined DMARDs in early RA shows a beneficial effect $[41,42]$. We previously demonstrated that patients with early RA had significantly higher average cIMT values and more plaque than healthy controls matched for $\mathrm{CV}$ risk factors. cIMT was pre-
Table 2

Univariate analysis of the relationship between change in flowmediated dilatation and GTN-mediated dilatation, features of RA and CV risk factors in 31 patients with early RA

\begin{tabular}{|c|c|c|c|}
\hline & $\mathbf{R}^{2}$ & $\beta$ coeff & $\mathrm{P}$ \\
\hline \multicolumn{4}{|l|}{ FMD: } \\
\hline RF presence & - & - & 0.037 \\
\hline \multicolumn{4}{|l|}{ Log CRP level } \\
\hline At week 0 & 0.173 & -0.946 & 0.020 \\
\hline At week 52 & 0.319 & -1.700 & 0.001 \\
\hline \multicolumn{4}{|l|}{ ESR } \\
\hline At week 0 & 0.142 & -1.451 & 0.037 \\
\hline At week 52 & 0.001 & -0.065 & 0.91 \\
\hline Change in GMD & 0.428 & 0.487 & $<0.001$ \\
\hline Carotid IMT at baseline & 0.196 & -10.22 & 0.013 \\
\hline Age & 0.346 & -0.133 & $<0.001$ \\
\hline Post menopausal status & - & - & 0.002 \\
\hline \multicolumn{4}{|l|}{ GMD: } \\
\hline \multicolumn{4}{|l|}{ Log CRP level } \\
\hline At week 0 & 0.214 & -0.394 & 0.006 \\
\hline At week 52 & 0.431 & -0.693 & $<0.001$ \\
\hline Change in FMD & 0.428 & 0.880 & $<0.001$ \\
\hline Carotid IMT at baseline & 0.232 & -3.89 & 0.007 \\
\hline Age & 0.206 & -0.035 & 0.012 \\
\hline Pack year history & 0.173 & -0.148 & 0.022 \\
\hline Ever smoking & - & - & 0.02 \\
\hline \multicolumn{4}{|l|}{ LDL } \\
\hline At week 0 & 0.173 & -0.561 & 0.086 \\
\hline At week 52 & 0.352 & -0.552 & 0.015 \\
\hline
\end{tabular}

Parameters showing statistically significant relationships are included. Bold values are statistically significant.

$\mathrm{CRP}=\mathrm{C}$-reactive protein; $\mathrm{CV}=$ cardiovascular; $\mathrm{ESR}=$ erythrocyte sedimentation rate; FMD = flow-mediated dilatation; $\mathrm{GMD}=\mathrm{GTN}$ mediated dilatation; GTN = glyceryl trinitrate; IMT = intima-media thickening; LDL = low-density lipoprotein; RA = rheumatoid arthritis; $\mathrm{RF}=$ rheumatoid factor

dicted by age and CRP level at first presentation with RA. A recent small study demonstrated that baseline cIMT in patients with established RA predicted development of $\mathrm{CV}$ events over the next five years [43]. Our results suggest that baseline CRP, ESR and RF may be useful prognostic markers for CV disease along with non-invasive measures of vascular function, including cIMT, FMD and GMD.

The lack of improvement in traditional CV risk factors in RA patients despite the improvement in FMD and GMD, which were both positively correlated with improvement in CRP, further implicates inflammation in arterial function impairment. 
Moreover, it is likely that endothelial function in RA primarily depends on the control of inflammatory activity rather than the specific treatment, as demonstrated by improvement with a variety of effective anti-rheumatic agents [16,44-46]. MTX was shown to reduce overall mortality by $60 \%$ primarily by reducing mortality from coronary heart disease [47]. The mechanism by which MTX provides CV protection might be explained at least in part by suppression of systemic inflammation. Although endothelial dysfunction has been reported in RA patients treated with long-term MTX [48], the improvement of endothelial function in our patients might be explained by early suppression of inflammation compared with the treatment of established RA patients with chronic inflammatory effects on vessels. In another study, reversal of endothelial dysfunction in patients with long-standing severe RA was only transient in response to TNF inhibitors, despite good control of systemic inflammation, suggesting that structural vascular changes might preclude more prolonged effects [45]. A recent demonstration that abnormal FMD was associated with longer disease duration in patients with established RA also supports the concept that endothelial dysfunction progresses and becomes less reversible over time [49].

Traditional CV risk factors identified from epidemiological studies such as hyperlipidaemia, smoking and older age may interact to damage the endothelium and smooth muscle in asymptomatic patients in the same way as they are known to interact to determine the risk of clinical CV endpoints [50]. Our data demonstrate that improvement in GMD, a marker of endothelial and smooth muscle dysfunction, after one year of treatment of early RA was significantly negatively associated with pack year history of smoking. Cigarette smoking increases oxidative stress because of low circulating levels of antioxidants and increased levels of oxygen-derived free radicals and lipid peroxides that degrade NO, leading to endothelial dysfunction [51,52]. Thus, smoking history may have a specific impact on the capacity of the endothelium and smooth muscle to respond to the anti-inflammatory effects of treatment. In a study of patients with longstanding RA, where those with a history of $C V$ disease or $C V$ risk factors including smoking were excluded, GMD in the RA patients was no different to that of age- and sex-matched controls or of the healthy control subjects in the current study [49]. These data suggest the hypothesis that inflammatory arthritis in the absence of $\mathrm{CV}$ risk factors does not promote arterial smooth muscle damage.

\section{Conclusions}

This study shows that inflammation severity is closely associated with functional and structural arterial wall changes in patients with early RA. Early control of inflammation is associated with improved arterial function which may reduce atherosclerotic progression.

\section{Competing interests}

The authors declare that they have no competing interests.

\section{Authors' contributions}

$\mathrm{SH}, \mathrm{TM}$ and $\mathrm{RT}$ were involved in conception, design, acquisition, analysis, interpretation of data and drafting and revising the manuscript: All authors read and approved the final manuscript.

\section{Acknowledgements}

Supported by grants from the PA Hospital Foundation, Australian Rotary Health Research Fund and a scholarship from the Ministry of Higher Education, United Arab Emirates. RT is supported by Arthritis Queensland. We thank Matthew Brown for helpful discussions. There are no commercial affiliations.

\section{References}

1. del Rincon ID, Williams K, Stern MP, Freeman GL, Escalante A: High incidence of cardiovascular events in a rheumatoid arthritis cohort not explained by traditional cardiac risk factors. Arthritis Rheum 2001, 44:2737-2745.

2. Wolfe F, Mitchell DM, Sibley JT, Fries JF, Bloch DA, Williams CA, Spitz PW, Haga M, Kleinheksel SM, Cathey MA: The mortality of rheumatoid arthritis. Arthritis Rheum 1994, 37:481-494.

3. Banks M, Flint J, Bacon P, Kitas G: Rheumatoid arthritis is an independent risk factor for ischaemic heart disease. Arthritis Rheum 2000, 1909:S358.

4. Lutzky V, Hannawi S, Thomas R: Cells of the synovium in rheumatoid arthritis. Dendritic cells. Arthritis Res Ther 2007, 9:219.

5. Pignoli P, Tremoli E, Poli A, Oreste P, Paoletti R: Intimal plus medial thickness of the arterial wall: a direct measurement with ultrasound imaging. Circulation 1986, 74:1399-1406.

6. Lorenz MW, Markus HS, Bots ML, Rosvall M, Sitzer M: Prediction of clinical cardiovascular events with carotid intima-media thickness: a systematic review and meta-analysis. Circulation 2007, 115:459-467.

7. Salonen JT, Salonen R: Ultrasound B-mode imaging in observational studies of atherosclerotic progression. Circulation 1993, 87:1156-65.

8. Hannawi S, Haluska B, Marwick TH, Thomas R: Atherosclerotic disease is increased in recent onset rheumatoid arthritis: a critical role for inflammation. Arthritis Res Ther 2007, 9:R116.

9. Raitakari OT, Seale JP, Celermajer DS: Impaired vascular responses to nitroglycerin in subjects with coronary atherosclerosis. Am J Cardiol 2001, 87:217-219. A218.

10. Joannides R, Haefeli WE, Linder L, Richard V, Bakkali EH, Thuillez C, Luscher TF: Nitric oxide is responsible for flow-dependent dilatation of human peripheral conduit arteries in vivo. Circulation 1995, 91:1314-1319.

11. Corretti MC, Anderson TJ, Benjamin EJ, Celermajer D, Charbonneau F, Creager MA, Deanfield J, Drexler H, Gerhard-Herman M, Herrington D, Vallance P, Vita J, Vogel R: Guidelines for the ultrasound assessment of endothelial-dependent flow-mediated vasodilation of the brachial artery: a report of the International Brachial Artery Reactivity Task Force. J Am Coll Cardiol 2002, 39:257-265.

12. Adams MR, Robinson J, McCredie R, Seale JP, Sorensen KE, Deanfield JE, Celermajer DS: Smooth muscle dysfunction occurs independently of impaired endothelium-dependent dilation in adults at risk of atherosclerosis. J Am Coll Cardiol 1998, 32:123-127.

13. Bergholm R, Leirisalo-Repo M, Vehkavaara S, Makimattila S, Taskinen MR, Yki-Jarvinen $\mathrm{H}$ : Impaired responsiveness to $\mathrm{NO}$ in newly diagnosed patients with rheumatoid arthritis. Arterioscler Thromb Vasc Biol 2002, 22:1637-1641.

14. Gonzalez-Juanatey C, Testa A, Garcia-Castelo A, Garcia-Porrua C, Llorca J, Gonzalez-Gay MA: Active but transient improvement of endothelial function in rheumatoid arthritis patients undergoing long-term treatment with anti-tumor necrosis factor alpha antibody. Arthritis Rheum 2004, 51:447-450.

15. Modena MG, Bonetti L, Coppi F, Bursi F, Rossi R: Prognostic role of reversible endothelial dysfunction in hypertensive postmenopausal women. J Am Coll Cardiol 2002, 40:505-510. 
16. Hansel S, Lassig G, Pistrosch F, Passauer J: Endothelial dysfunction in young patients with long-term rheumatoid arthritis and low disease activity. Atherosclerosis 2003, 170:177-180.

17. Vaudo G, Marchesi S, Gerli R, Allegrucci R, Giordano A, Siepi D, Pirro M, Shoenfeld Y, Schillaci G, Mannarino E: Endothelial dysfunction in young patients with rheumatoid arthritis and low disease activity. Ann Rheum Dis 2004, 63:31-35.

18. Cardillo C, Schinzari F, Mores N, Mettimano M, Melina D, Zoli A, Ferraccioli G: Intravascular tumor necrosis factor alpha blockade reverses endothelial dysfunction in rheumatoid arthritis. Clin Pharmacol Ther 2006, 80:275-281.

19. Hingorani AD, Cross J, Kharbanda RK, Mullen MJ, Bhagat K, Taylor M, Donald AE, Palacios M, Griffin GE, Deanfield JE, MacAllister RJ, Vallance $P$ : Acute systemic inflammation impairs endotheliumdependent dilatation in humans. Circulation 2000, 102:994-999.

20. Raza K, Thambyrajah J, Townend JN, Exley AR, Hortas C, Filer A, Carruthers DM, Bacon PA: Suppression of inflammation in primary systemic vasculitis restores vascular endothelial function: lessons for atherosclerotic disease? Circulation 2000, 102:1470-1472.

21. Lima DS, Sato El, Lima VC, Miranda F Jr, Hatta FH: Brachial endothelial function is impaired in patients with systemic lupus erythematosus. J Rheumato/ 2002, 29:292-297.

22. Sari I, Okan T, Akar S, Cece H, Altay C, Secil M, Birlik M, Onen F, Akkoc N: Impaired endothelial function in patients with ankylosing spondylitis. Rheumatology (Oxford) 2006, 45:283-286.

23. Carroll L, Hannawi S, Marwick T, Thomas R: Rheumatoid arthritis: links with cardiovascular disease and the receptor for advanced glycation end products. Wien Med Wochenschr 2006, 156:42-52.

24. Arnett FC, Edworthy SM, Bloch DA, McShane DJ, Fries JF, Cooper NS, Healey LA, Kaplan SR, Liang MH, Luthra HS, et al:: The American Rheumatism Association 1987 revised criteria for the classification of rheumatoid arthritis. Arthritis Rheum 1988, 31:315-324.

25. O'Dell JR, Haire CE, Erikson N, Drymalski W, Palmer W, Eckhoff PJ, Garwood V, Maloley P, Klassen LW, Wees S, Klein H, Moore GF: Treatment of rheumatoid arthritis with methotrexate alone, sulfasalazine and hydroxychloroquine, or a combination of all three medications. N Engl J Med 1996, 334:1287-1291.

26. Proudman SM, Keen HI, Stamp LK, Lee AT, Goldblatt F, Ayres OC, Rischmueller M, James MJ, Hill CL, Caughey GE, Cleland LG: Response-driven combination therapy with conventional disease-modifying antirheumatic drugs can achieve high response rates in early rheumatoid arthritis with minimal glucocorticoid and nonsteroidal anti-inflammatory drug use. Semin Arthritis Rheum 2007, 37:99-111.

27. Roberts LJ, Cleland LG, Thomas R, Proudman SM: Early combination disease modifying antirheumatic drug treatment for rheumatoid arthritis. Med J Aust 2006, 184:122-125.

28. Saunders SA, Capell HA, Stirling A, Vallance R, Kincaid W, McMahon $A D$, Porter DR: Triple therapy in early active rheumatoid arthritis: a randomized, single-blind, controlled trial comparing step-up and parallel treatment strategies. Arthritis Rheum 2008, 58:1310-1317.

29. Kooij SM van der, Allaart CF, Dijkmans BA, Breedveld FC: Innovative treatment strategies for patients with rheumatoid arthritis. Curr Opin Rheumatol 2008, 20:287-294.

30. Raitakari OT, Celermajer DS: Flow-mediated dilatation. $\mathrm{Br} J \mathrm{Clin}$ Pharmacol 2000, 50:397-404.

31. Stata corp: Stata statistical software: Release 9.0. College station, Texas: Stata corp. LP; 2005.

32. Wal AC van der, Piek JJ, de Boer OJ, Koch KT, Teeling P, Loos CM van der, Becker $A E$ : Recent activation of the plaque immune response in coronary lesions underlying acute coronary syndromes. Heart 1998, 80:14-18.

33. Pasceri V, Yeh ET: A tale of two diseases: atherosclerosis and rheumatoid arthritis. Circulation 1999, 100:2124-2126.

34. Ross R: Atherosclerosis - an inflammatory disease. $N$ Engl J Med 1999, 340:115-126.

35. Gabriel SE, Crowson CS, Kremers HM, Doran MF, Turesson C, O'Fallon WM, Matteson EL: Survival in rheumatoid arthritis: a population-based analysis of trends over $\mathbf{4 0}$ years. Arthritis Rheum 2003, 48:54-58.

36. Van Doornum S, McColl G, Jenkins A, Green DJ, Wicks IP. Screening for atherosclerosis in patients with rheumatoid arthritis: comparison of two in vivo tests of vascular function. Arthritis Rheum 2003, 48:72-80.

37. Datta D, Ferrell WR, Sturrock RD, Jadhav ST, Sattar N: Inflammatory suppression rapidly attenuates microvascular dysfunction in rheumatoid arthritis. Atherosclerosis 2007, 192:391-395.

38. Galarraga B, Khan F, Kumar P, Pullar T, Belch JJ: C-reactive protein: the underlying cause of microvascular dysfunction in rheumatoid arthritis. Rheumatology (Oxford) 2008, 47:1780-1784.

39. Quinn MA, Emery P: Window of opportunity in early rheumatoid arthritis: possibility of altering the disease process with early intervention. Clin Exp Rheumatol 2003, 21:S154-157.

40. Anderson JJ, Wells G, Verhoeven AC, Felson DT: Factors predicting response to treatment in rheumatoid arthritis: the importance of disease duration. Arthritis Rheum 2000, 43:22-29.

41. Landewe RB, Boers M, Verhoeven AC, Westhovens R, Laar MA van de, Markusse HM, van Denderen JC, Westedt ML, Peeters AJ, Dijkmans BA, Jacobs $P$, Boonen A, Heijde DM van der, Linden S van der: COBRA combination therapy in patients with early rheumatoid arthritis: long-term structural benefits of a brief intervention. Arthritis Rheum 2002, 46:347-356.

42. Puolakka K, Kautiainen $\mathrm{H}$, Mottonen $\mathrm{T}$, Hannonen $\mathrm{P}$, Korpela $\mathrm{M}$, Julkunen $\mathrm{H}$, Luukkainen R, Vuori K, Paimela L, Blafield H, Hakala M Leirisalo-Repo M: Impact of initial aggressive drug treatment with a combination of disease-modifying antirheumatic drugs on the development of work disability in early rheumatoid arthritis: a five-year randomized followup trial. Arthritis Rheum 2004, 50:55-62.

43. Gonzalez-Juanatey C, Llorca J, Martin J, Gonzalez-Gay MA Carotid intima-media thickness predicts the development of cardiovascular events in patients with rheumatoid arthritis. Semin Arthritis Rheum 2009, 38:366-371.

44. Maki-Petaja KM, Booth AD, Hall FC, Wallace SM, Brown J, McEniery CM, Wilkinson IB: Ezetimibe and simvastatin reduce inflammation, disease activity, and aortic stiffness and improve endothelial function in rheumatoid arthritis. $J \mathrm{Am}$ Coll Cardiol 2007, 50:852-858.

45. Bosello S, Santoliquido A, Zoli A, Di Campli C, Flore R, Tondi P, Ferraccioli G: TNF-alpha blockade induces a reversible but transient effect on endothelial dysfunction in patients with long-standing severe rheumatoid arthritis. Clin Rheumatol 2008, 27:833-839.

46. Gonzalez-Juanatey C, Llorca J, Vazquez-Rodriguez TR, Diaz-Varela N, Garcia-Quiroga H, Gonzalez-Gay MA: Short-term improvement of endothelial function in rituximab-treated rheumatoid arthritis patients refractory to tumor necrosis factor alpha blocker therapy. Arthritis Rheum 2008, 59:1821-1824.

47. Choi HK, Hernan MA, Seeger JD, Robins JM, Wolfe F: Methotrexate and mortality in patients with rheumatoid arthritis: a prospective study. Lancet 2002, 359:1173-1177

48. Gonzalez-Juanatey C, Llorca J, Testa A, Revuelta J, Garcia-Porrua C, Gonzalez-Gay MA: Increased prevalence of severe subclinical atherosclerotic findings in long-term treated rheumatoid arthritis patients without clinically evident atherosclerotic disease. Medicine (Baltimore) 2003, 82:407-413.

49. Kerekes G, Szekanecz Z, Der H, Sandor Z, Lakos G, Muszbek L, Csipo I, Sipka S, Seres I, Paragh G, Kappelmayer J, Szomjak E, Veres K, Szegedi G, Shoenfeld Y, Soltesz P: Endothelial dysfunction and atherosclerosis in rheumatoid arthritis: a multiparametric analysis using imaging techniques and laboratory markers of inflammation and autoimmunity. I Rheumatol 2008, 35:398-406.

50. Celermajer DS, Sorensen KE, Spiegelhalter DJ, Georgakopoulos $D$, Robinson J, Deanfield JE: Aging is associated with endothelial dysfunction in healthy men years before the age-related decline in women. J Am Coll Cardiol 1994, 24:471-476.

51. Murohara T, Kugiyama K, Ohgushi M, Sugiyama S, Yasue H: Cigarette smoke extract contracts isolated porcine coronary arteries by superoxide anion-mediated degradation of EDRF. Am J Physiol 1994, 266:H874-880.

52. Sanderson KJ, van Rij AM, Wade CR, Sutherland WH: Lipid peroxidation of circulating low density lipoproteins with age, smoking and in peripheral vascular disease. Atherosclerosis 1995, 118:45-51. 